Cochrane Database of Systematic Reviews

\title{
Psychological interventions for reducing postoperative morbidity in dental surgery in adults (Protocol)
}

van Wijk A, Buchanan $\mathrm{H}$, Coulson $\mathrm{N}$

van Wijk A, Buchanan $\mathrm{H}$, Coulson N.

Psychological interventions for reducing postoperative morbidity in dental surgery in adults.

Cochrane Database of Systematic Reviews 2017, Issue 9. Art. No.: CD007777.

DOI: 10.1002/14651858.CD007777.pub2.

www.cochranelibrary.com 
TABLE OF CONTENTS

HEADER 1

REASON FOR WITHDRAWAL FROM PUBLICATION 
[Intervention Protocol]

\section{Psychological interventions for reducing postoperative morbidity in dental surgery in adults}

Arjen van Wijk ${ }^{1}$, Heather Buchanan², Neil Coulson²

1Social Dentistry and Behavioural Sciences, Academic Centre for Dentistry Amsterdam (ACTA), Amsterdam, Netherlands. 2 Institute of Work, Health \& Organisations, University of Nottingham, Nottingham, UK

Contact address: Arjen van Wijk, Social Dentistry and Behavioural Sciences, Academic Centre for Dentistry Amsterdam (ACTA), Gustav Mahlerlaan 3004, Amsterdam, 1081 LA, Netherlands. a.vwijk@acta.nl.

Editorial group: Cochrane Oral Health Group.

Publication status and date: Withdrawn from publication for reasons stated in the review, published in Issue 9, 2017.

Citation: van Wijk A, Buchanan H, Coulson N. Psychological interventions for reducing postoperative morbidity in dental surgery in adults. Cochrane Database of Systematic Reviews 2017, Issue 9. Art. No.: CD007777. DOI: 10.1002/14651858.CD007777.pub2.

Copyright ( 2017 The Cochrane Collaboration. Published by John Wiley \& Sons, Ltd.

\section{REASON FOR WITHDRAWAL FROM PUBLICATION}

Protocol withdrawn, it is out of date and does not meet current Cochrane methodological standards.

The editorial group responsible for this previously published document have withdrawn it from publication.

WHAT'S NEW

\begin{tabular}{lll}
\hline Date & Event & Description \\
\hline 12 September 2017 & Amended & $\begin{array}{l}\text { Protocol withdrawn, it is out of date and does not meet current } \\
\text { Cochrane methodological standards. }\end{array}$ \\
\hline
\end{tabular}

\section{SOURCES OF SUPPORT}

\section{Internal sources}

- Dutch Cochrane Centre, Netherlands.

\section{External sources}

- British Academy, UK.

Small grant to develop the protocol 